\title{
$\begin{array}{ll}\text { Research Square } & \begin{array}{l}\text { Preprints are preliminary reports that have not undergone peer review. } \\ \text { They should not be considered conclusive, used to inform clinical practice, } \\ \text { or referenced by the media as validated information. }\end{array}\end{array}$
}

\section{A Clinical Decision Support System is Associated with Reduced Loss to Follow-Up Among Patients Receiving HIV Treatment in Kenya: A Cluster Randomised Trial}

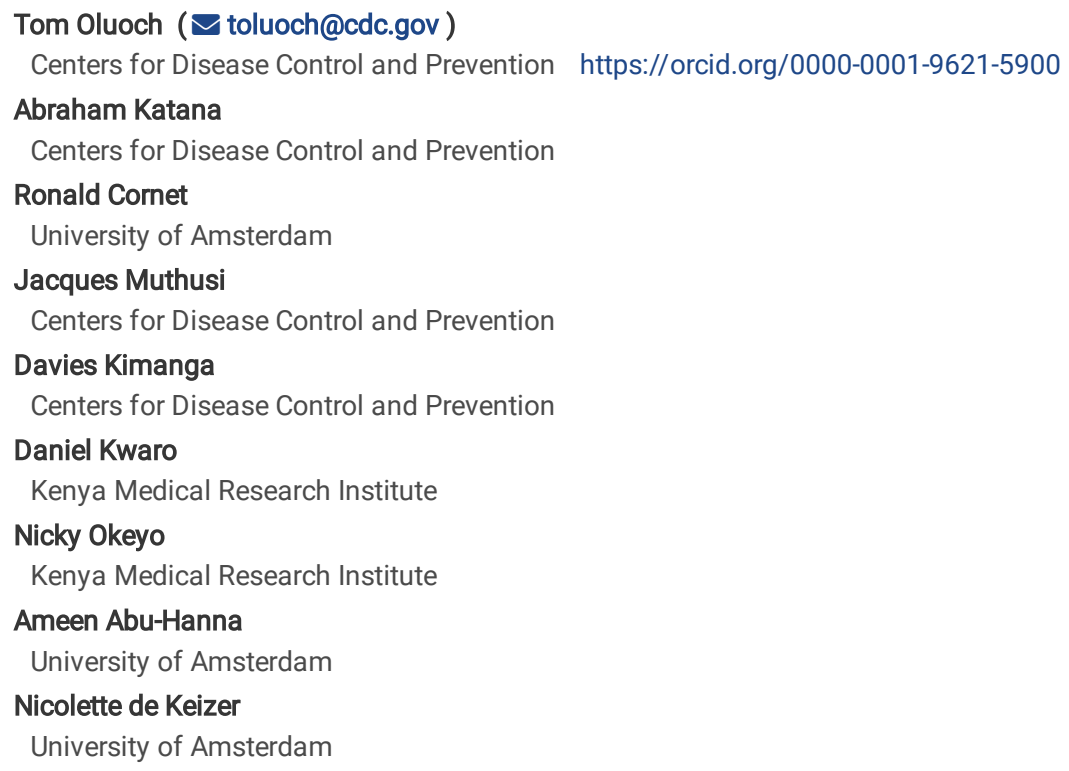

Version of Record: A version of this preprint was published at BMC Medical Informatics and Decision Making on December 1st, 2021. See the published version at https://doi.org/10.1186/s12911-021-01718-0. 


\section{Abstract}

Background Loss to follow-up (LFTU) among HIV patients continues to be a major obstacle to achieving treatment goals with the risk of failure to achieve viral suppression and thereby increased HIV transmission. Although use of clinical decision support systems (CDSSs) has been shown to improve adherence to HIV clinical guidance, this is the first study ever conducted to show its effect on LTFU in low-resource settings.

Methods We analyzed data from a cluster-randomized trial conducted at $20 \mathrm{HIV}$ clinics in western Kenya to assess the effects of a CDSS implemented as alerts on an electronic health records (EHR) system on: (1) the proportion of patients that were LTFU, (2) LTFU patients traced and successfully referred back to treatment, and (3) the time from enrollment on treatment to LTFU.

Results Among eligible 5,901 patients receiving ART, $40.6 \%(n=2,396)$ were LTFU at any time during the study period. Lack of a CDSS was associated with higher LTFU among the ART patients (Adjusted Odds Ratio - aOR=1.45, 95\% Cl: 1.35-1.55). The proportions of patients linked back to treatment were 29.1\% (95\% Cl: $27.6-0.6)$ and $34.1 \%(95 \% \mathrm{Cl}: 32.1-36.2)$ in EHR only and EHR with CDSS sites respectively. There was no statistically significant association between the use of a CDSS and time to LTFU.

Conclusion A CDSS can potentially improve quality of care through reduction of LTFU among HIV patients in a resource-limited country. CDSS is only part of the solution to LTFU and would be most effective if implemented together with other interventions.

\section{Background}

The 2018 version of the report of the Joint United Nations Program on HIV/AIDS (UNAIDS) indicates that approximately 23.3 million (61.5\%) of 37.9 million HIV-infected people globally are on life-saving antiretroviral therapy (ART). Sub-Saharan Africa (SSA) is home to 25.6 million HIV-infected persons of which $64 \%$ ( $n=16.4$ million) were receiving ART at the end of 2018 (1). The UNAIDS Fast-Track goals, commonly referred to as the $90-90-90$ goals, recommend that countries should have $90 \%$ of HIV-infected persons know their HIV status, $90 \%$ of those who know their HIV positive status initiated on ART and $90 \%$ of those on treatment achieving viral suppression by 2020 in order to assure global epidemic control (2). Good adherence to treatment is essential in achieving viral suppression and reduction in HIV transmission (3). Many countries in SSA still suffer high loss to follow-up (LTFU) of patients on ART, poor adherence to treatment and low retention rates. Studies have shown that LTFU in SSA countries could be as high as $40 \%$ among the general population after 36 months of enrollment on treatment (4-6) and as high as $57 \%$ among youth (7).

While patient demographics, behavior and related factors such as limited knowledge of the need for good adherence and appointment keeping significantly contribute to LTFU (7-9), effective alerts in clinical information systems used by care providers to identify patients who miss their appointments and strong tracking systems could potentially reduce cases of LTFU. Previous studies have shown that EHRs with CDSS can effectively track clinic attendance, flag individual patients who fail to show up for their appointment (10). Once identified, community-based social workers follow-up LTFU patients and provide appropriate education, counseling and support to ensure they return to the clinic to continue treatment in accordance with Kenya national HIV treatment guidelines (11). The weak data systems used in SSA are often incapable of providing timely information on patients who have transferred to other clinics, have died or have missed their monthly appointments. Innovative means such as computerized reminders in electronic health records (EHR) have been shown to improve patient follow-up in chronic care and adherence to treatment guidelines at population and individual patient levels $(12,13)$.

EHR with a clinical decision support system (CDSS), implemented as alerts or reminders that are displayed on a computer screen in the clinic or printed out routinely, have been used to provide information on selected clinical and process indicators that often improve individual patient care through better adherence to guidelines. Such indicators include trends and thresholds in vital signs, treatment history, co-infections and clinic attendance/appointments (14, 15). A CDSS often recommend appropriate action to be taken after comparing specific patient parameters to pre-determined values stored in the EHR's internal database based on guidelines. A systematic review by van de Velde et al showed that CDSSs could be more effective when suggestions are patient-specific compared to group-based recommendations (16). Automated alerts and reminders with actionable recommendations are increasingly used as key tools for HIV care as the number of patients enrolled on ART increases and health facilities need efficient, accurate and reliable systems for early identification and appropriate follow-up action on those that are LTFU. No previous studies have described the associations between use of a CDSS and LTFU in HIV treatment. This is the first paper ever to show the effect of an alert-based CDSS on LTFU in a low-resource setting.

\section{Methods}

We conducted a prospective, cluster randomized controlled study in Siaya County, western Kenya, between September $1^{\text {st }}, 2012$ and January $31^{\text {st }}, 2014$ to assess the effect of an EHR with CDSS compared to EHR only on timely identification of patients experiencing immunological treatment failure and appropriate action taken (17). In this study we performed secondary analysis of the data to assess the effect of a CDSS on LTFU. The study was conducted, and reported, in adherence to the CONSORT guidelines.

Setting and patient population: Siaya county, where the study was conducted, has one of the highest HIV prevalence in Kenya. Approximately $17.8 \%$ of adults aged 15-49 were HIV-positive compared to the national prevalence of 5.6\% (10). The study sites consisted of 20 health facilities where the Kenya Medical Research Institute (KEMRI) provides data management support for routine health service delivery and research.

All patients aged two years or older were included in the study. We included all patients who were already receiving ART prior to implementation of the EHR at the clinic and during the data collection period but excluded those that were newly initiating treatment after the $9^{\text {th }}$ month of the study. 
Lost to follow-up (LTFU) patients: The Kenyan Ministry of Health's (MOH) HIV treatment guidelines (adapted from WHO's HIV consolidated treatment guidelines, 2012) describes a patient that is LTFU as: "a client who has not turned up or come back to the clinic for either a clinical visit or refills for more than 90 days (3 months) from the last scheduled visit" $(11,18)$. Before a patient is classified as LTFU, he/she is considered a Defaulter. According to the Kenya $\mathrm{MOH}$ guidelines: "A defaulter is a client who has not turned up for either a clinical visit or refills 7 days after their scheduled appointment date (11). In clinics where paper-based systems are used to document patients treatment records, the daily (or in some cases weekly) appointment list is prepared by manually reviewing individual patient charts and retrieving the date of next visit. At the end of each clinic day, the staff responsible for data management (often data clerks or nurses) review the Daily Attendance Register to identify names of patients who missed their appointments and this is used to classify defaulting patients or those that are LTFU before tracing is initiated through social or community health workers. Timely tracing enables the community health worker to offer the necessary education, counseling and support to the patient and refer them back to the clinic to resume treatment.

Randomization: The KEMRI data management team used block randomization to assign the eligible 20 health facilities into two groups - EHR only or EHR plus CDSS, matched by the $\mathrm{MOH}$ level and number of patients enrolled on HIV care. Level 2 facility (Dispensary) is defined as: headed by a nurse, offers basic out-patient and some preventive services; Level 3 (Health Center), headed by a clinical officer, offers out-patient, maternal child health and limited in-patient services; Level 4 (District Hospital), headed by a physician, is a district referral facility and offers emergency, outpatient and in-patient services (19). For each $\mathrm{MOH}$ level, whenever a clinic was assigned to the EHR with CDSS group through a random selection, a same-level clinic with comparable number of patients on HIV care was assigned to the EHR-only group. Each group had 1-3 levels of health facilities. Level 1 (Community clinics) were not included since they don't offer HIV treatment services. The KEMRI data management team were not involved in data analysis and the CDC statisticians who performed the analysis were blinded to the allocation of clinics into the respective arms of the study.

LTFU and Electronic Health Records: In clinics with EHR systems, appointment lists are automatically generated from the computerized system at the start of the clinic day. Lists of defaulters and patients that are LFTU are automatically generated at the end of each week. The 20 HIV clinics in Siaya County where KEMRI supported data management had an EHR system referred to as Comprehensive Care Centre Patient Application Database (C-PAD). The C-PAD EHR was originally developed as a standalone application using Visual Basic for Applications in 2007. It underwent several enhancements and a CDSS was integrated into the 2012 version prior to the start of this study. Following the randomization described above, the intervention group had an EHR with CDSS functionality while the CDSS was turned off (muted) in the control group. The main difference between the two systems is that the version with a CDSS identifies individuals that are LTFU and recommends appropriate action at individual level (included in the patient charts) while the version that is an EHR-only does not make any recommendations beyond generating a weekly list of patients who missed appointments. Health workers in the sites with EHR and CDSS were trained on the appropriate action to take whenever alerts were encountered. Such action included immediate follow-up of patient or inclusion of a note in the patient chart for action during the next clinic visit.

For the two study groups (EHR only and EHR+CDSS), clinicians recorded data on the paper form (the so-called blue card) during the consultation, and the data clerk entered this data into the computer on the same day of clinic visit. For patients who miss an appointment and meet the criteria for defaulter or LTFU, the system generates an alert which is printed out and included in the patient charts with recommendation for appropriate follow-up action. KEMRI data managers routinely reviewed the data and any missing or unusual values were sent back to the clinician via the data clerks for completion, correction or confirmation.

Outcome measures: The primary outcome measure for this study was a comparison of the proportion of patients receiving HIV treatment that were LTFU. Secondary outcomes measures were the proportion of LTFU patients traced and successfully linked back to treatment, and time from ART initiation to LTFU.

Data management: The KEMRI data management team abstracted selected variables from the EHR. Individual patient records were de-identified and assigned study numbers that could not be traced back to the patient. Analytic datasets were created and duplicate entries deleted. Such duplicate entries may have resulted from erroneous creation of new records for patients who could not be correctly identified at the registration desk during clinic visits but were eventually correctly matched and linked to previous visits. Patients were coded as LFTU if they met the MOH's definition. Those that were LTFU but were traced and referred back to the facility and successfully re-initiated treatment were still counted as LTFU. Approximately $15 \%$ of patients that were LTFU, were lost more than once during the study period and the proportions were comparable across the groups.

Statistical analysis: The sample size calculation was adapted from the method used in the main study reported in (17). We calculated means with 95\% confidence intervals and medians with inter-quartile ranges to summarize continuous variables. We used the Kruskal-Wallis test to compare distribution of medians and ANOVA to test for mean differences by outcome status. We used generalized estimating equations to analyze clustered data to determine predictors of LTFU over time and Cox hazard regression to identify risk factors associated with time to first loss to follow-up. Kaplan-Meier survival function plots and hazard ratios from the clustered Cox regression were used to measure statistical differences in the survival curves comparing time-to-event data and were expressed as a $p$-value. Data were censored at the last follow-up visit. The multi-variable analysis was adjusted for the following patient-level covariates: age, sex, marital status, CD-4 category, WHO stage, and treatment regimen; and site-level variables (level of health facility). We used Stata (version 14.0) [Stata Corp, Austin, Texas] and Statistical Analysis Software (SAS ${ }^{\circledR} 9.4$ Base SAS. Cary, NC: SAS Institute Inc., 2014) for both data management and statistical analysis.

Missing data considerations: The data contained missing values for some of the patient-level covariates. We conducted Little's test[1] for missing completely at random (MCAR) on these covariates. A non-significant result ( $p$-value=1.000) was obtained indicating that there was no relationship between the missingness of data and the observed or missing values. Therefore, complete case analysis (CCA) was applied to perform statistical analysis.

Ethical review: The study was reviewed in accordance with the Centers for Disease Control and Prevention (CDC) human research protection procedures and was determined to be research, but CDC investigators did not interact with human subjects or have access to identifiable data or specimens for research purposes. The Kenya Medical Research Institute's (KEMRI) Ethical Review Committee reviewed and approved the study. All data was de-identified by the KEMRI staff participating in this study prior to analysis. 
This trial is registered with ClinicalTrials.gov, number NCT01634802

\section{Footnote:}

[1] Little, R. (1998). Test for missing completely at random for multivariate data with missing values. Journal of American Statistical Association. 83 (404), $1198-1202$

\section{Results}

A total of 5,901 patients were included in the analyses as they were receiving ART at the 20 health facilities and had at least one clinic visit prior to the installation of the CDSS as well as during the first 9 of the 12 months of the study. Among the patients, those aged $25-49$ years constituted $67.8 \%$ while a higher number of females were registered (62.7\%) compared to men. Of the patients on ART, $52.5 \%$ were married and $43.1 \%$ were classified in WHO stage III (indicative of active illness). (Table 1).

\section{Patients lost to follow-up:}

Among eligible ART patients, $40.6 \%(n=2,396 / 5,901)$ were LTFU at any time during the study period i.e. those that missed the last scheduled clinic appointments for at least 90 days and were traced and referred back to the clinic plus those that were never traced. ART patients in the EHR-only group had a LTFU rate of $45.6 \%$ (95\% Confidence Interval - $\mathrm{Cl}: 44.0$ - 47.2) $95 \%$ compared to $32.8 \%$ (95\% Cl: 30.9 - 34.7) in the EHR with CDSS group (Table 2).

Lack of a CDSS was associated with higher LTFU among ART patients (Odds Ratio - OR=1.42, 95\% Cl: 1.32 - 1.53). The association was confirmed after adjusting for age-group, sex, marital status, CD4 category and WHO clinical stage, (aOR=1.39, 95\% Cl: 1.28 - 1.50) (Table 3).

\section{Proportion of patients linked back to care and treatment:}

The overall proportion of ART patients that were LTFU and were traced and linked back to treatment was 30.9\% (95\% Cl: 29.7 - 32.1). The proportion of ART patients linked back to treatment were $29.1 \%(95 \%$ Cl: $27.6-30.6)$ and $34.1 \%(95 \%$ Cl: $32.1-36.2)$ in the EHR-only and EHR with CDSS sites respectively.

\section{Time to LTFU:}

The median time from ART initiation to first LTFU was 61.0 months, (Inter-Quartile Range - IQR: 41.9 - 74.9). The respective median times in the EHR-only and EHR with CDSS sites were 59.7 months (IQR - IQR: 43.5 - 72.9) and 62.2 months (IQR 40.2 - 76.8). Figure 2 shows the time from ART initiation to the first LTFU. The results from the Cox regression models (not presented in Tables) showed non-significant Hazard Ratios associating a CDSS to time to LTFU: (Hazard Ratio - HR = 1.09 (95\% Cl: $0.67-1.78)$ ). After adjusting for age-group, sex, marital status, CD4 category and WHO clinical staging, the adjusted HR $(\mathrm{aHR}=1.08(95 \% \mathrm{Cl}: 0.65-1.80))$.

\section{Discussion}

Our study showed that clinics without a CDSS had a $40 \%$ higher proportion of ART patients who were LTFU compared to those with a CDSS. Nearly half of the patients actively receiving ART had been lost to follow up at least once during the 12 month study period. This is similar to study by Clouse et al (20). The CDSS generated alerts that were printed out and placed in the individual patient charts to notify the clinical staff when patients missed their appointments (classified by the Kenyan Ministry of Health guidelines as defaulters) (11). Based on the finding of our study we believe that the individual patient level alerts may have been effective in identifying defaulting patients leading to tracing action and getting them back on pre-ART care or ART before they could be classified as LTFU.

The proportion of ART patients that were LTFU at least once and were traced and linked back to treatment was higher in the sites with a CDSS than those with EHR only. Printouts/alerts in the individual patient charts generated by the CDSS reminded the clinical staff to intensify efforts, in collaboration with peer educators, community health and social workers to trace the LTFU patients, counsel them and link them back to treatment. This is consistent with studies by Wilson et al and Semeere et al, which showed that use of electronic health records was associated with effective tracing of patients that are LTFU (21, 22). However, the CDSS was not associated with the time from ART initiation to LTFU. This could be due to selection bias as we only included patients that were not LTFU at the start of the study as well as the short study period of 12 months. Additionally, the duration that a patient takes before they are LTFU is influenced by several factors; other studies show that patient's behavioral characteristics, clinical processes and provider-related factors such as location and volume of patients receiving care at the facility could also contribute to patients becoming defaulters or LTFU $(9,23)$.

HIV patients who are lost to follow-up are unlikely to adhere to treatment guidelines and to achieve viral suppression. This comes with potential risks like higher mortality due to treatment failure, co-infection with opportunistic illnesses and likelihood of transmission of HIV to uninfected sexual partners (24). Interventions such as use of enhanced vital statistics and patient encounter simulations have been shown to enhance patient retention and improve linkage of chronic care patients who are LTFU back to treatment in resource-limited settings $(21,22)$. Integration of innovative solutions such as short message system (SMS) based reminders sent directly from an EHR's CDSS to a patient's cell phone improves clinic attendance, compliance with medication and other positive behavior which lead to better treatment outcomes (25). Our study, based on a stronger design and large sample size, provides early evidence of the important role that individual patient level alerts through a CDSS plays in improving adherence to HIV treatment guidelines and reducing LTFU in resource-limited settings. For a country like Kenya which had about 1 million patients receiving ART at the end of 2018, the use of a CDSS has the potential to reduce the LTFU of up to 128,000 patients ( $40 \%$ reduction of LTFU) and contribute to the tracing and linking back to care up to nearly 40,000 patients that are LTFU (approximately 33\% of all patients LTFU). As the number of HIV patients receiving ART increases following the release of the 2016 Edition of WHO's 
consolidated guidelines on the use of antiretroviral drugs for treating and preventing HIV infection that recommend universal treatment for all HIV infected persons irrespective of age, clinical presentation or pregnancy status (18) the use of a CDSS to enhance quality of care and reduce LTFU becomes indispensable. This need is more acute in sub-Saharan Africa where HIV disease burden is highest and health systems to support treatment programs weakest.

Our study had a few limitations: As the study was conducted in Ministry of Health-owned health facilities which often have limited resources such as staffing, reliable electric power and key supplies, documenting all clinic attendance and results of patient tracking was often challenging. These challenges affected the study sites in equal measure. During the data collection period, the KEMRI staff directly involved in the study ensured that any missing data was collected during subsequent patient visit and recorded as accurately as possible. The sample size for this study was quite large, enhancing the precision of results generated from the analyses. Our study showed that only one-third of the patients that were LTFU were linked back to HIV care or treatment. Although this figure is low, sites with a CDSS implementation had a much higher proportion of patients traced and linked to care and treatment compared to those without. It is worth noting that a CDSS is only one of the potential solutions for reducing LTFU and tracing of patients and should be implemented together with other interventions such as enhanced patient education, provider related characteristics (e.g. improved patient waiting time, streamlined services) and client-friendly services that help improve clinic attendance as recommended in several studies $(9,23,25)$.

Since 2014, Kenya has implemented interventions such as improved contract tracing though patients' mobile phones, enhanced adherence counseling, innovative community support services improve retention and reduce LTFU. In 2018, the country introduced multi-month prescription and dispensing of drugs among stable patients with the aim of reducing the number of clinic visits and decongesting clinics thereby reducing waiting time. Future work should investigate which co-interventions work in low resource settings.

\section{Conclusion}

An Alert-based CDSS implemented as part of an EHR can contribute to enhanced quality of HIV treatment through reduction of LTFU among HIV patients receiving ART in resource-limited settings in Kenya. A CDSS is only part of the solution to LTFU and would be most effective if implemented together with other interventions such as enhanced contact tracing, patient education, multi-month dispensing of drugs to reduce congestion, structural improvement of health facilities and provider characteristics (e.g. health worker training).

\section{Declarations}

Ethics approval and consent to participate: The study was reviewed in accordance with the Centers for Disease Control and Prevention (CDC) human research protection procedures and was determined to be research, but CDC investigators did not interact with human subjects or have access to identifiable data or specimens for research purposes. The Kenya Medical Research Institute's (KEMRI) Ethical Review Committee reviewed and approved the study. This study is a secondary analysis of de-identified data and IRBs approved it with no requirement for additional consent from the participants.

Consent for publication: CDC's Office of the Associate Director for Science at the Division of Global HIV and TB approved the publication of this manuscript on $15^{\text {th }}$ May 2020.

Competing interests: All authors declare no conflict of interest in conducting the study and preparation of the manuscript for publication.

Funding and role of funders: This research study has been supported by the US President's Emergency Plan for AIDS Relief (PEPFAR) through CDC under the terms of Grant no. 1U19GH00041. PEPFAR did not have any direct engagement at any stage of the study.

Authors' contributions: TO, AK, RC, AAH and NdK conceptualized and designed the study. TO, RC, AAH, NdK provided the informatics context while AK, DPK and DK provided the clinical context on guidelines. JM, NO provided data management support and JM conducted the statistical analysis. TO, AK, RC and NdK drafted the manuscript and all authors reviewed and edited it and approved its submission for publication.

Acknowledgements: We thank the Director of KEMRI and his staff for the approval of this study. We also thank all the staff at the clinics in Siaya County that supported the data collection for this study and to PEPFAR for funding this study.

Availability of data and materials: The datasets generated and/or analysed during this study are not publicly available in line with the KEMRI Guidelines. However, the corresponding author may seek KEMRI's permission to share the de-identified data upon reasonable request.

\section{References}

1. UNAIDS. 2017 Global HIV Statistics: Fact-Sheet UNAIDS Website2018 [July 2018:[Available from: https://www.unaids.org/en/resources/fact-sheet.

2. The Joint United Nations Program on HIV/AIDS. Fast Track: Ending the AIDS Epidemic by 2030 Online: UNAIDS; 2015 [Available from: http://www.unaids.org/sites/default/files/media_asset/JC2686_WAD2014report_en.pdf.

3. Oldenburg CE, Barnighausen T, Tanser F, Iwuji CC, De Gruttola V, Seage GR, 3rd, et al. Antiretroviral Therapy to Prevent HIV Acquisition in Serodiscordant Couples in a Hyperendemic Community in Rural South Africa. Clin Infect Dis. 2016;63(4):548-54.

4. Bayitondere S, Biziyaremye F, Kirk CM, Magge H, Hann K, Wilson K, et al. Assessing retention in care after 12 months of the Pediatric Development Clinic implementation in rural Rwanda: a retrospective cohort study. BMC Pediatr. 2018;18(1):65.

5. Clouse K, Vermund SH, Maskew M, Lurie MN, MacLeod W, Malete G, et al. Mobility and Clinic Switching Among Postpartum Women Considered Lost to HIV Care in South Africa. J Acquir Immune Defic Syndr. 2017;74(4):383-9. 
6. Schechter J, Bakor AB, Kone A, Robinson J, Lue K, Senturia K. Exploring loss to follow-up among women living with HIV in Prevention of Mother to Child Transmission programmes in Cote d'Ivoire. Glob Public Health. 2014;9(10):1139-51.

7. Ojwang VO, Penner J, Blat C, Agot K, Bukusi EA, Cohen CR. Loss to follow-up among youth accessing outpatient HIV care and treatment services in Kisumu, Kenya. AIDS Care. 2016;28(4):500-7.

8. Chandiwana N, Sawry S, Chersich M, Kachingwe E, Makhathini B, Fairlie L. High loss to follow-up of children on antiretroviral treatment in a primary care HIV clinic in Johannesburg, South Africa. Medicine (Baltimore). 2018;97(29):e10901.

9. Tweya H, Oboho IK, Gugsa ST, Phiri S, Rambiki E, Banda R, et al. Loss to follow-up before and after initiation of antiretroviral therapy in HIV facilities in Lilongwe, Malawi. PLoS One. 2018;13(1):e0188488.

10. Government of Kenya. Kenya AIDS Response Progress Report 2013. In: Council NAC, editor. Nairobi, Kenya: National AIDS Control Council; 2014.

11. Kenyan Ministry of Health. Guidelines for Antiretroviral Therapy in Kenya 4th Edition. Nairobi, Kenya: 2011 Re-print. In: (NASCOP) NASCP, editor. Nairobi, Kenya: National AIDS/STI Control Program (NASCOP); 2012.

12. Oluoch T, Kwaro D, Ssempijja V, Katana A, Langat P, Okeyo N, et al. Better adherence to pre-antiretroviral therapy guidelines after implementing an electronic medical record system in rural Kenyan HIV clinics: a multicenter pre-post study. Int J Infect Dis. 2015;33:109-13.

13. Oluoch T, Santas X, Kwaro D, Were M, Biondich P, Bailey C, et al. The effect of electronic medical record-based clinical decision support on HIV care in resource-constrained settings: a systematic review. Int J Med Inform. 2012;81(10):e83-92.

14. Garg AX, Adhikari NK, McDonald H, Rosas-Arellano MP, Devereaux PJ, Beyene J, et al. Effects of computerized clinical decision support systems on practitioner performance and patient outcomes: a systematic review. JAMA. 2005;293(10):1223-38.

15. Van de Velde S, Heselmans A, Delvaux N, Brandt L, Marco-Ruiz L, Spitaels D, et al. A systematic review of trials evaluating success factors of interventions with computerised clinical decision support. Implement Sci. 2018;13(1):114.

16. Roshanov PS, Misra S, Gerstein HC, Garg AX, Sebaldt RJ, Mackay JA, et al. Computerized clinical decision support systems for chronic disease management: a decision-maker-researcher partnership systematic review. Implement Sci. 2011;6:92.

17. Oluoch T, Katana A, Kwaro D, Santas X, Langat P, Mwalili S, et al. Effect of a clinical decision support system on early action on immunological treatment failure in patients with HIV in Kenya: a cluster randomised controlled trial. Lancet HIV. 2016;3(2):e76-84.

18. World Health Organizations. Consolidated guidelines on the use of antiretroviral drugs for treating and preventing HIV infection. In: HIV, editor. Geneva, Switzerland: World Health Organizations; 2016.

19. Kenya National Coordinating Agency on Population and Development. Service Provision Assessment (SPA) 2010. Nairobi, Kenya: Kenya National Coordinating Agency for Population and Development; 2010.

20. Clouse K, Pettifor A, Shearer K, Maskew M, Bassett J, Larson B, et al. Loss to follow-up before and after delivery among women testing HIV positive during pregnancy in Johannesburg, South Africa. Trop Med Int Health. 2013;18(4):451-60.

21. Semeere A, Freeman E, Wenger M, Glidden D, Bwana M, Kanyesigye M, et al. Updating vital status by tracking in the community among patients with epidemic Kaposi sarcoma who are lost to follow-up in sub-Saharan Africa. BMC Cancer. 2017;17(1):611.

22. Wilson KS, Mugo C, Bukusi D, Inwani I, Wagner AD, Moraa H, et al. Simulated patient encounters to improve adolescent retention in HIV care in Kenya: study protocol of a stepped-wedge randomized controlled trial. Trials. 2017;18(1):619.

23. Shabalala FS, Vernooij E, Pell C, Simelane N, Masilela N, Spiegelman D, et al. Understanding reasons for discontinued antiretroviral treatment among clients in test and treat: a qualitative study in Swaziland. J Int AIDS Soc. 2018;21 Suppl 4:e25120.

24. Langebeek N, Gisolf EH, Reiss P, Vervoort SC, Hafsteinsdottir TB, Richter C, et al. Predictors and correlates of adherence to combination antiretroviral therapy (ART) for chronic HIV infection: a meta-analysis. BMC Med. 2014;12:142.

25. Tegegne AS, Ndlovu P, Zewotir T. Factors affecting first month adherence due to antiretroviral therapy among HIV-positive adults at Felege Hiwot Teaching and Specialized Hospital, north-western Ethiopia; a prospective study. BMC Infect Dis. 2018;18(1):83.

\section{Tables}


Table 1

Characteristics of CDSS ART patients by outcome status, N $=5901$

\begin{tabular}{|c|c|c|c|c|c|c|c|c|c|c|c|}
\hline \multirow[b]{2}{*}{ Characteristic } & \multicolumn{3}{|c|}{ Died/Transfer out } & \multicolumn{3}{|l|}{ Reenrolled } & \multicolumn{3}{|c|}{ Lost to follow-up } & \multicolumn{2}{|c|}{ Alive and on care } \\
\hline & $\begin{array}{l}\text { Unweighted } \\
\mathrm{n} / \mathrm{N}\end{array}$ & $\begin{array}{l}\text { Weighted } \\
\% \\
\text { (or } \\
\text { Median) }\end{array}$ & $\begin{array}{l}95 \% \\
\mathrm{Cl} \\
\text { (or } \\
\mathrm{lQR} \text { ) }\end{array}$ & $\begin{array}{l}\text { Unweighted } \\
n / N\end{array}$ & $\begin{array}{l}\text { Weighted } \\
\% \\
\text { (or } \\
\text { Median) }\end{array}$ & $\begin{array}{l}95 \% \\
\mathrm{Cl} \\
\text { (or } \\
\mathrm{lQR} \text { ) }\end{array}$ & $\begin{array}{l}\text { Unweighted } \\
\mathrm{n} / \mathrm{N}\end{array}$ & $\begin{array}{l}\text { Weighted } \\
\% \\
\text { (or } \\
\text { Median) }\end{array}$ & $\begin{array}{l}95 \% \\
\mathrm{Cl} \\
\text { (or } \\
\mathrm{lQR} \text { ) }\end{array}$ & $\begin{array}{l}\text { Unweighted } \\
\mathrm{n} / \mathrm{N}\end{array}$ & $\begin{array}{l}\text { Wei } \\
\% \\
\text { (or } \\
\text { Me }\end{array}$ \\
\hline \multicolumn{12}{|l|}{ Age group, years } \\
\hline$<15$ years & $69 / 478$ & 14.4 & $\begin{array}{l}(11.3- \\
17.6)\end{array}$ & $81 / 478$ & 16.9 & $\begin{array}{l}(13.6- \\
20.3)\end{array}$ & $180 / 478$ & 37.7 & $\begin{array}{l}(33.3- \\
42.0)\end{array}$ & $148 / 478$ & 31 \\
\hline $15-24$ years & $124 / 740$ & 16.8 & $\begin{array}{l}(14.1- \\
19.4)\end{array}$ & $92 / 740$ & 12.4 & $\begin{array}{l}(10.1- \\
14.8)\end{array}$ & $284 / 740$ & 38.4 & $\begin{array}{l}(34.9- \\
41.9)\end{array}$ & $240 / 740$ & 32. \\
\hline $25-49$ years & $619 / 4003$ & 15.5 & $\begin{array}{l}(14.3- \\
16.6)\end{array}$ & $562 / 4003$ & 14 & $\begin{array}{l}(13.0- \\
15.1)\end{array}$ & $1646 / 4003$ & 41.1 & $\begin{array}{l}(39.6- \\
42.6)\end{array}$ & $1176 / 4003$ & 29. \\
\hline $50+$ years & $89 / 611$ & 14.6 & $\begin{array}{l}(11.8- \\
17.4)\end{array}$ & $77 / 611$ & 12.6 & $\begin{array}{l}(10.0- \\
15.2)\end{array}$ & $262 / 611$ & 42.9 & $\begin{array}{l}(39.0- \\
46.8)\end{array}$ & $183 / 611$ & 30 \\
\hline Total & $907 / 5901$ & 15.4 & $\begin{array}{l}(14.4- \\
16.3)\end{array}$ & $831 / 5901$ & 14.1 & $\begin{array}{l}(13.2- \\
15.0)\end{array}$ & $2396 / 5901$ & 40.6 & $\begin{array}{l}(39.4- \\
41.9)\end{array}$ & $1767 / 5901$ & 29. \\
\hline \multicolumn{12}{|l|}{ Sex } \\
\hline Male & $304 / 2209$ & 13.8 & $\begin{array}{l}(12.3- \\
15.2)\end{array}$ & $292 / 2209$ & 13.2 & $\begin{array}{l}(11.8- \\
14.6)\end{array}$ & $893 / 2209$ & 40.4 & $\begin{array}{l}(38.4- \\
42.5)\end{array}$ & $720 / 2209$ & 32.1 \\
\hline Female & $603 / 3692$ & 16.3 & $\begin{array}{l}(15.1- \\
17.5)\end{array}$ & $539 / 3692$ & 14.6 & $\begin{array}{l}(13.5- \\
15.7)\end{array}$ & $1503 / 3692$ & 40.7 & $\begin{array}{l}(39.1- \\
42.3)\end{array}$ & $1047 / 3692$ & 28. \\
\hline Total & $907 / 5901$ & 15.4 & $\begin{array}{l}(14.4- \\
16.3)\end{array}$ & $831 / 5901$ & 14.1 & $\begin{array}{l}(13.2- \\
15.0)\end{array}$ & $2396 / 5901$ & 40.6 & $\begin{array}{l}(39.4- \\
41.9)\end{array}$ & $1767 / 5901$ & 29.1 \\
\hline \multicolumn{12}{|l|}{ Marital status } \\
\hline Married & $443 / 3097$ & 14.3 & $\begin{array}{l}(13.1- \\
15.5)\end{array}$ & $405 / 3097$ & 13.1 & $\begin{array}{l}(11.9- \\
14.3)\end{array}$ & $1297 / 3097$ & 41.9 & $\begin{array}{l}(40.1- \\
43.6)\end{array}$ & $952 / 3097$ & 30. \\
\hline Divorced/Separated & $65 / 271$ & 24 & $\begin{array}{l}(18.9- \\
29.1)\end{array}$ & $29 / 271$ & 10.7 & $\begin{array}{l}(7.0- \\
14.4)\end{array}$ & $78 / 271$ & 28.8 & $\begin{array}{l}(23.4- \\
34.2)\end{array}$ & $99 / 271$ & $36 . !$ \\
\hline Widow & $167 / 1074$ & 15.5 & $\begin{array}{l}(13.4- \\
17.7)\end{array}$ & $173 / 1074$ & 16.1 & $\begin{array}{l}(13.9- \\
18.3)\end{array}$ & $469 / 1074$ & 43.7 & $\begin{array}{l}(40.7- \\
46.6)\end{array}$ & $265 / 1074$ & $24:$ \\
\hline Single & $152 / 948$ & 16 & $\begin{array}{l}(13.7- \\
18.4)\end{array}$ & $144 / 948$ & 15.2 & $\begin{array}{l}(12.9- \\
17.5)\end{array}$ & $357 / 948$ & 37.7 & $\begin{array}{l}(34.6- \\
40.7)\end{array}$ & $295 / 948$ & 31. \\
\hline Total & $907 / 5901$ & 15.4 & $\begin{array}{l}(14.4- \\
16.3)\end{array}$ & $831 / 5901$ & 14.1 & $\begin{array}{l}(13.2- \\
15.0)\end{array}$ & $2396 / 5901$ & 40.6 & $\begin{array}{l}(39.4- \\
41.9)\end{array}$ & $1767 / 5901$ & 29.1 \\
\hline \multicolumn{12}{|l|}{ CD4 category } \\
\hline$<350$ & $874 / 5669$ & 15.4 & $\begin{array}{l}(14.5- \\
16.4)\end{array}$ & $793 / 5669$ & 14 & $\begin{array}{l}(13.1- \\
14.9)\end{array}$ & $2287 / 5669$ & 40.3 & $\begin{array}{l}(39.1- \\
41.6)\end{array}$ & $1715 / 5669$ & $30 .:$ \\
\hline $350-500$ & $16 / 111$ & 14.4 & $\begin{array}{l}(7.9- \\
20.9)\end{array}$ & $16 / 111$ & 14.4 & $\begin{array}{l}(7.9- \\
20.9)\end{array}$ & $55 / 111$ & 49.5 & $\begin{array}{l}(40.2- \\
58.9)\end{array}$ & $24 / 111$ & 21.1 \\
\hline$>500$ & $17 / 121$ & 14 & $\begin{array}{l}(7.9- \\
20.2)\end{array}$ & $22 / 121$ & 18.2 & $\begin{array}{l}(11.3- \\
25.1)\end{array}$ & $54 / 121$ & 44.6 & $\begin{array}{l}(35.8- \\
53.5)\end{array}$ & $28 / 121$ & 23. \\
\hline Total & $907 / 5901$ & 15.4 & $\begin{array}{l}(14.4- \\
16.3)\end{array}$ & $831 / 5901$ & 14.1 & $\begin{array}{l}(13.2- \\
15.0)\end{array}$ & $2396 / 5901$ & 40.6 & $\begin{array}{l}(39.4- \\
41.9)\end{array}$ & $1767 / 5901$ & 29.1 \\
\hline \multicolumn{12}{|l|}{ WHO stage } \\
\hline WHO I & $118 / 1194$ & 9.9 & $\begin{array}{l}(8.2- \\
11.6)\end{array}$ & $154 / 1194$ & 12.9 & $\begin{array}{l}(11.0- \\
14.8)\end{array}$ & $471 / 1194$ & 39.4 & $\begin{array}{l}(36.7- \\
42.2)\end{array}$ & $451 / 1194$ & 37.1 \\
\hline WHO II & $206 / 1701$ & 12.1 & $\begin{array}{l}(10.6- \\
13.7)\end{array}$ & $218 / 1701$ & 12.8 & $\begin{array}{l}(11.2- \\
14.4)\end{array}$ & 766/1701 & 45 & $\begin{array}{l}(42.7- \\
47.4)\end{array}$ & $511 / 1701$ & 30 \\
\hline WHO III & $481 / 2543$ & 18.9 & $\begin{array}{l}(17.4- \\
20.4)\end{array}$ & $415 / 2543$ & 16.3 & $\begin{array}{l}(14.9- \\
17.8)\end{array}$ & $1029 / 2543$ & 40.5 & $\begin{array}{l}(38.6- \\
42.4)\end{array}$ & $618 / 2543$ & $24 .:$ \\
\hline WHO IV & $54 / 165$ & 32.7 & $\begin{array}{l}(25.6- \\
39.9)\end{array}$ & $19 / 165$ & 11.5 & $\begin{array}{l}(6.6- \\
16.4)\end{array}$ & $54 / 165$ & 32.7 & $\begin{array}{l}(25.6- \\
39.9)\end{array}$ & $38 / 165$ & 23 \\
\hline Total & $907 / 5901$ & 15.4 & $\begin{array}{l}(14.4- \\
16.3)\end{array}$ & $831 / 5901$ & 14.1 & $\begin{array}{l}(13.2- \\
15.0)\end{array}$ & $2396 / 5901$ & 40.6 & $\begin{array}{l}(39.4- \\
41.9)\end{array}$ & $1767 / 5901$ & 29.1 \\
\hline
\end{tabular}




\begin{tabular}{|c|c|c|c|c|c|c|c|c|c|c|c|}
\hline \multirow[b]{2}{*}{ First line regime } & \multicolumn{3}{|c|}{ Died/Transfer out } & \multicolumn{3}{|l|}{ Reenrolled } & \multicolumn{3}{|c|}{ Lost to follow-up } & \multicolumn{2}{|c|}{ Alive and on care } \\
\hline & & & & & & & & & & & \\
\hline Nevirapine & $716 / 4887$ & 14.7 & $\begin{array}{l}(13.7- \\
15.6)\end{array}$ & $739 / 4887$ & 15.1 & $\begin{array}{l}(14.1- \\
16.1)\end{array}$ & $2113 / 4887$ & 43.2 & $\begin{array}{l}(41.8- \\
44.6)\end{array}$ & $1319 / 4887$ & 27 \\
\hline Efavirenz & $185 / 954$ & 19.4 & $\begin{array}{l}(16.9- \\
21.9)\end{array}$ & $89 / 954$ & 9.3 & $\begin{array}{l}(7.5- \\
11.2)\end{array}$ & $274 / 954$ & 28.7 & $\begin{array}{l}(25.8- \\
31.6)\end{array}$ & $406 / 954$ & 42.1 \\
\hline Other & $6 / 60$ & 10 & $\begin{array}{l}(2.4- \\
17.6)\end{array}$ & $3 / 60$ & 5 & $\begin{array}{l}(0.0- \\
10.5)\end{array}$ & $9 / 60$ & 15 & $\begin{array}{l}(6.0- \\
24.0)\end{array}$ & $42 / 60$ & 70 \\
\hline Total & $907 / 5901$ & 15.4 & $\begin{array}{l}(14.4- \\
16.3)\end{array}$ & $831 / 5901$ & 14.1 & $\begin{array}{l}(13.2- \\
15.0)\end{array}$ & $2396 / 5901$ & 40.6 & $\begin{array}{l}(39.4- \\
41.9)\end{array}$ & $1767 / 5901$ & 29. \\
\hline \multicolumn{12}{|l|}{ Art adherence } \\
\hline Satisfactory & $502 / 848$ & 59.2 & $\begin{array}{l}(55.9- \\
62.5)\end{array}$ & $55 / 848$ & 6.5 & $\begin{array}{l}(4.8- \\
8.1)\end{array}$ & $134 / 848$ & 15.8 & $\begin{array}{l}(13.3- \\
18.3)\end{array}$ & $157 / 848$ & 18. \\
\hline Unsatisfactory & $6 / 7$ & 85.7 & $\begin{array}{l}(59.7- \\
100)\end{array}$ & $0 / 7$ & . & $(.-)$. & $0 / 7$ & . & $(.-)$. & $1 / 7$ & 14: \\
\hline Total & $907 / 5901$ & 15.4 & $\begin{array}{l}(14.4- \\
16.3)\end{array}$ & $831 / 5901$ & 14.1 & $\begin{array}{l}(13.2- \\
15.0)\end{array}$ & $2396 / 5901$ & 40.6 & $\begin{array}{l}(39.4- \\
41.9)\end{array}$ & $1767 / 5901$ & 29. \\
\hline
\end{tabular}

Table 2

Effect of CDSS on Retention and Attrition of ART patients in Kenya

\begin{tabular}{|c|c|c|c|c|c|c|c|c|c|c|c|}
\hline \multirow[b]{2}{*}{$\begin{array}{l}\text { Site type } \\
\text { (Control or } \\
\text { Intervention) }\end{array}$} & \multicolumn{3}{|c|}{ Died/Transfer out } & \multicolumn{3}{|l|}{ Reenrolled } & \multicolumn{3}{|c|}{ Lost to follow-up } & \multicolumn{2}{|c|}{ Alive and on care } \\
\hline & $\begin{array}{l}\text { Unweighted } \\
\mathrm{n} / \mathrm{N}\end{array}$ & $\begin{array}{l}\text { Weighted } \\
\%\end{array}$ & $\begin{array}{l}95 \% \\
\mathrm{Cl}\end{array}$ & $\begin{array}{l}\text { Unweighted } \\
\mathrm{n} / \mathrm{N}\end{array}$ & $\begin{array}{l}\text { Weighted } \\
\%\end{array}$ & $\begin{array}{l}95 \% \\
\mathrm{Cl}\end{array}$ & $\begin{array}{l}\text { Unweighted } \\
\mathrm{n} / \mathrm{N}\end{array}$ & $\begin{array}{l}\text { Weighted } \\
\%\end{array}$ & $\begin{array}{l}95 \% \\
\mathrm{Cl}\end{array}$ & $\begin{array}{l}\text { Unweighted } \\
\mathrm{n} / \mathrm{N}\end{array}$ & $\begin{array}{l}\text { Weighted } \\
\%\end{array}$ \\
\hline \multicolumn{12}{|l|}{$\begin{array}{l}\text { Patients } \\
\text { receiving } \\
\text { ART }\end{array}$} \\
\hline Control & $546 / 3595$ & 15.2 & $\begin{array}{l}(14.0- \\
16.4)\end{array}$ & $497 / 3595$ & 13.8 & $\begin{array}{l}(12.7- \\
15.0)\end{array}$ & $1640 / 3595$ & 45.6 & $\begin{array}{l}(44.0- \\
47.2)\end{array}$ & $912 / 3595$ & 25.4 \\
\hline Intervention & $361 / 2306$ & 15.7 & $\begin{array}{l}(14.2- \\
17.1)\end{array}$ & $334 / 2306$ & 14.5 & $\begin{array}{l}(13.0- \\
15.9)\end{array}$ & $756 / 2306$ & 32.8 & $\begin{array}{l}(30.9- \\
34.7)\end{array}$ & $855 / 2306$ & 37.1 \\
\hline Total & $907 / 5901$ & 15.4 & $\begin{array}{l}(14.4- \\
16.3)\end{array}$ & $831 / 5901$ & 14.1 & $\begin{array}{l}(13.2- \\
15.0)\end{array}$ & $2396 / 5901$ & 40.6 & $\begin{array}{l}(39.4- \\
41.9)\end{array}$ & $1767 / 5901$ & 29.9 \\
\hline
\end{tabular}


Table 3

Factors associated with loss to follow-up over time among ART patients, N = 5901

\begin{tabular}{|c|c|c|c|c|c|c|c|}
\hline & LFTU outcome & $\begin{array}{l}\text { Unadjusted } \\
\text { odds ratios }\end{array}$ & & & $\begin{array}{l}\text { Adjusted } \\
\text { odds ratios }\end{array}$ & & \\
\hline Characteristic & Frequency & OR $(95 \% \mathrm{Cl})$ & P-value & $\begin{array}{l}\text { Global } \\
\text { p-value }\end{array}$ & OR $(95 \% \mathrm{Cl})$ & P-value & $\begin{array}{l}\text { Global } \\
\text { p-value }\end{array}$ \\
\hline \multicolumn{8}{|l|}{ Site status } \\
\hline Intervention & 2306 & & & & & & \\
\hline Control & 3595 & $1.42(1.32-1.53)$ & $<.001$ & $<.001$ & $1.39(1.28-1.50)$ & $<.001$ & $<.001$ \\
\hline \multicolumn{8}{|l|}{ Age group, years } \\
\hline$<15$ years & 478 & & & & & & \\
\hline $15-24$ years & 740 & $0.86(0.73-1.02)$ & 0.077 & 0.099 & $0.87(0.70-1.07)$ & 0.181 & 0.323 \\
\hline $25-49$ years & 4003 & $0.99(0.87-1.13)$ & 0.894 & & $0.96(0.79-1.17)$ & 0.685 & \\
\hline $50+$ years & 611 & $1.00(0.85-1.18)$ & 0.981 & & $1.00(0.79-1.26)$ & 0.984 & \\
\hline \multicolumn{8}{|l|}{ Sex } \\
\hline Male & 2209 & & & & & & \\
\hline Female & 3692 & $1.01(0.94-1.09)$ & 0.713 & 0.713 & $0.98(0.89-1.06)$ & 0.575 & 0.575 \\
\hline \multicolumn{8}{|l|}{ Marital status } \\
\hline Divorced/Separated & 271 & & & & & & \\
\hline Married & 3097 & $1.50(1.23-1.84)$ & $<.001$ & $<.001$ & $1.40(1.13-1.72)$ & 0.002 & 0.004 \\
\hline Single & 948 & $1.47(1.18-1.82)$ & $<.001$ & & $1.41(1.11-1.80)$ & 0.005 & \\
\hline Widow & 1074 & $1.67(1.35-2.07)$ & $<.001$ & & $1.50(1.21-1.87)$ & $<.001$ & \\
\hline \multicolumn{8}{|l|}{ CD4 category } \\
\hline$<350$ & 5669 & & & & & & \\
\hline $350-500$ & 111 & $1.30(1.02-1.66)$ & 0.036 & 0.011 & & & \\
\hline$>500$ & 121 & $1.34(1.05-1.71)$ & 0.019 & & & & \\
\hline \multicolumn{8}{|l|}{ WHO stage } \\
\hline WHO IV & 165 & & & & & & \\
\hline WHO I & 1194 & $1.35(1.04-1.74)$ & 0.024 & & $1.22(0.92-1.62)$ & 0.165 & 0.073 \\
\hline WHO II & 1701 & $1.52(1.18-1.96)$ & 0.001 & & $1.35(1.03-1.78)$ & 0.033 & \\
\hline WHO III & 2543 & $1.36(1.06-1.75)$ & 0.016 & & $1.26(0.96-1.66)$ & 0.095 & \\
\hline \multicolumn{8}{|l|}{ First line regimen } \\
\hline Other & 60 & & & & & & \\
\hline Efavirenz & 954 & $1.90(1.09-3.32)$ & 0.024 & $<.001$ & $1.92(0.89-4.14)$ & 0.096 & $<.001$ \\
\hline Nevirapine & 4887 & $3.18(1.84-5.51)$ & $<.001$ & & $3.12(1.46-6.67)$ & 0.003 & \\
\hline
\end{tabular}

\section{Figures}




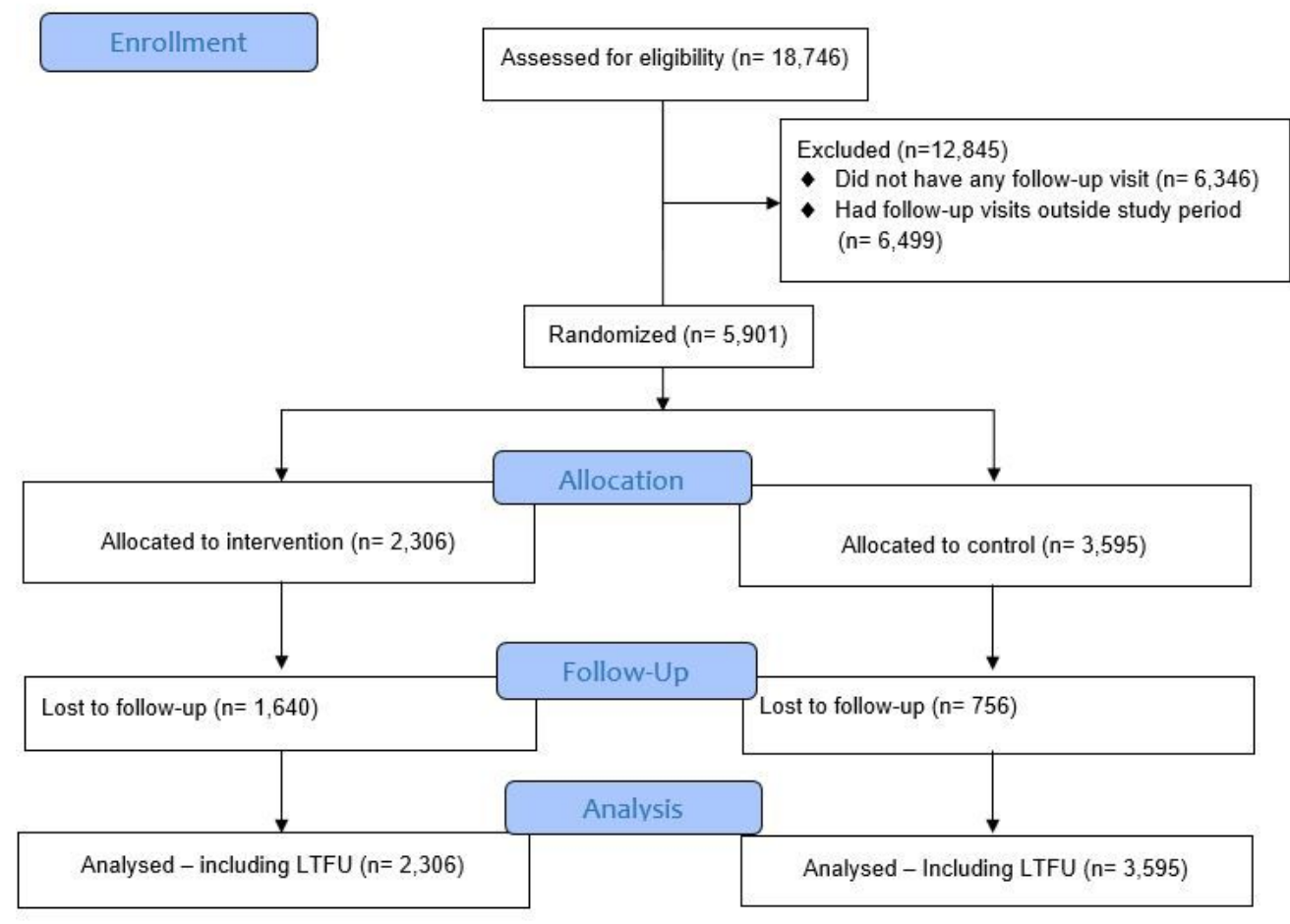

Figure 1

The study Profile

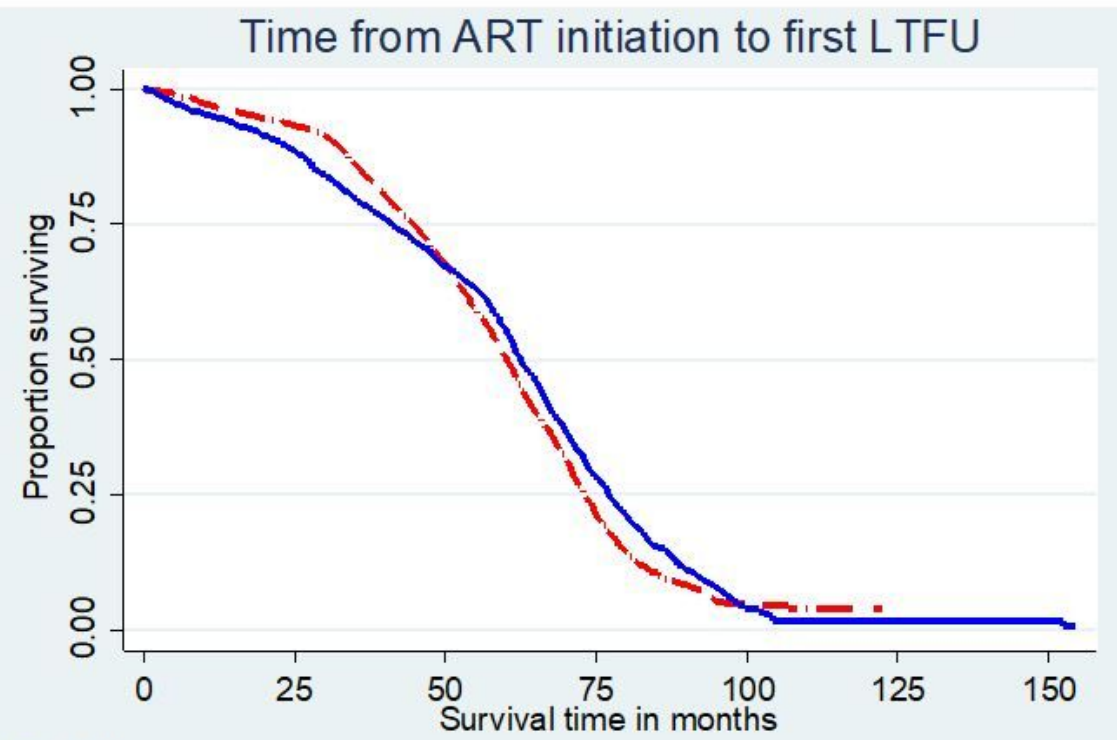

Number at risk

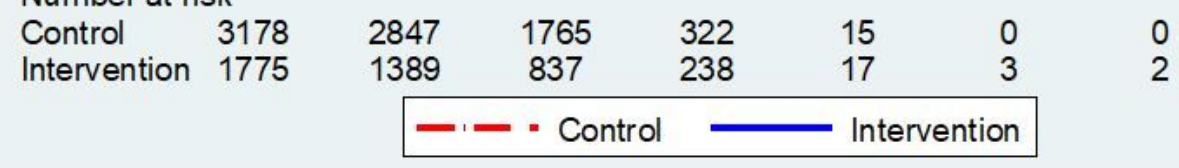

Figure 2

Time from ART initiation to first LTFU

\section{Supplementary Files}

This is a list of supplementary files associated with this preprint. Click to download.

- CONSORT2010ChecklistOluoch.doc 
Page 11/11 